\title{
Sucessão familiar no meio rural - uma análise com base em os Buddenbrook de Thomas Mann
}

\author{
Family succession in the rural environment - an analysis based on Thomas Mann's Buddenbrook \\ Sucesión familiar en el entorno rural - un análisis basado en los Buddenbrook de Thomas Mann
}

Recebido: 05/02/2021 | Revisado: 08/02/2021 | Aceito: 11/02/2021 | Publicado: 16/02/2021

Edcleyton José de Lima

ORCID: https://orcid.org/0000-0002-3635-1369 Universidade Federal do Agreste de Pernambuco, Brasil

E-mail: cley1020kj@gmail.com

Raquel Maria da Silva

ORCID: https://orcid.org/0000-0002-5503-2072

Universidade Federal Rural de Pernambuco, Brasil E-mail: Raquel.maria18@hotmail.com

Eliane Maria de Lima

ORCID: https://orcid.org/0000-0003-2426-672X Autarquia do Ensino Superior de Garanhuns, Brasil E-mail:elianelajedo@hotmail.com

Tallys Celso Mineiro

ORCID: https://orcid.org/0000-0001-8044-3503

Universidade Federal de Pernambuco, Brasil E-mail: tallyscelsomineiro@gmail.com

Daniela Moreira de Carvalho

ORCID: https://orcid.org/0000-0003-4720-7722

Universidade Federal do Agreste de Pernambuco, Brasil

E-mail: daniela.carvalho@ufape.edu.br

\begin{abstract}
Resumo
$\mathrm{Na}$ atualidade a sucessão familiar no meio rural ainda é um assunto que demanda estudos para elucidar a problemática que a cerca, mesmo com a ressignificação e a construção de novos padrões sociais. O presente trabalho tem como objetivo realizar uma análise no romance "Os Buddenbrook - Decadência de Uma Família”, correlacionando com as características encontradas nos dias atuais e os possíveis processos que podem levam ao sucesso ou ao fracasso da sucessão. Nos caminhos metodológicos foram realizadas pesquisas bibliográficas e documentais com caráter qualitativo, visando o aprofundamento sobre a sucessão familiar e todas as bases e pilares que a compõe. A pesquisa qualitativa aqui realizada é direcionada para a validação do objeto de estudo apresentado. Por consequência após análise dos acontecimentos contidos na ficção foi possível enfatizar que a sucessão familiar deve ser vista como um processo e não como um evento, sendo necessária a formação de sucessores e não somente de herdeiros. É necessário viabilizar processos de formações dos filhos e filhas, objetivando a aquisição de conhecimentos que possam serem utilizados na liderança das propriedades rurais e, consequentemente, na perpetuação dos negócios familiares. Os entraves apresentados no romance podem ser facilmente encontrados em espaços rurais no Brasil. Com base na obra de Thomas Mann, os temas abordados puderam ser discutidos, e constatou-se que as relações familiares formam os pilares na construção do sucessor, cabendo principalmente ao patriarca a tarefa de determinar a melhor forma de planejamento.

Palavras-chave: Empresa rural; Processo de sucessão; Pesquisa qualitativa.
\end{abstract}

\begin{abstract}
Currently, family succession in rural areas is still an issue that requires studies to elucidate the problem that surrounds it, even with the reframing and the construction of new social standards. The present work aims to carry out an analysis in the novel "The Buddenbrook - Decay of a Family", correlating with the characteristics found in the present day and the possible processes that can lead to the success or failure of the succession. In the methodological paths, bibliographical and documentary researches with qualitative character were carried out, aiming to deepen the family succession and all the bases and pillars that compose it. The qualitative research conducted here is aimed at validating the object of study presented. Consequently, after analyzing the events contained in the fiction, it was possible to emphasize that family succession should be seen as a process and not as an event, requiring the formation of successors and not only heirs. It is necessary to make training processes for sons and daughters viable, aiming at acquiring knowledge that can be used in the leadership of rural properties and, consequently, in the perpetuation of family businesses. The obstacles presented in the novel can be easily found in rural spaces in Brazil. Based on the work of
\end{abstract}


Thomas Mann, the topics covered could be discussed, and it was found that family relationships form the pillars in the construction of the successor, with the patriarch being primarily responsible for determining the best form of planning. Keywords: Rural company; Succession process; Qualitative research.

\begin{abstract}
Resumen
Actualmente, la sucesión familiar en el medio rural sigue siendo un tema que requiere estudios para dilucidar la problemática que la rodea, incluso con el replanteamiento y la construcción de nuevos estándares sociales. El presente trabajo tiene como objetivo realizar un análisis en la novela "The Buddenbrook - Decay of a Family", correlacionando con las características encontradas en la actualidad y los posibles procesos que pueden conducir al éxito o fracaso de la sucesión. En los recorridos metodológicos se realizaron investigaciones bibliográficas y documentales de carácter cualitativo, con el objetivo de profundizar en la sucesión familiar y todas las bases y pilares que la componen. La investigación cualitativa que aquí se realiza tiene como objetivo validar el objeto de estudio presentado. En consecuencia, luego de analizar los hechos contenidos en la ficción, se pudo enfatizar que la sucesión familiar debe ser vista como un proceso y no como un hecho, requiriendo la formación de sucesores y no solo herederos. Es necesario viabilizar los procesos de formación de hijos e hijas, con el objetivo de adquirir conocimientos que puedan ser utilizados en el liderazgo de las propiedades rurales y, en consecuencia, en la perpetuación de los negocios familiares. Los obstáculos presentados en la novela se pueden encontrar fácilmente en los espacios rurales de Brasil. A partir del trabajo de Thomas Mann, se pudieron discutir los temas tratados, y se encontró que las relaciones familiares forman los pilares en la construcción del sucesor, siendo el patriarca el principal responsable de determinar la mejor forma de planificación.
\end{abstract}

Palabras clave: Empresa rural; Proceso de sucesión; Investigación cualitativa.

\title{
1. Introdução
}

Ao passar dos séculos houve mudanças significativas no modo de viver do homem no campo, visto que ocorreram constantes migrações para a zona urbana, caracterizando o êxodo rural, portando a forma como a agricultura passou a ser vista determinou o êxito de muitas atividades agrícolas e a decadência de tantos outras. A modernização afetou drasticamente o modelo antigo de sucessão, caracterizando-o acerca de diversos agentes pessoais, interpessoais e sociais (Oliveira \& Filho, 2018).

O processo de sucessão familiar caracteriza-se como a transferência da posse de quaisquer negócios para seus descendentes, dando continuidade à trajetória objetivada pela família. Sendo assim, cabe ao gestor direcionar e analisar a melhor forma de transmitir a seus descendentes a gestão das fazendas, sítios ou pequenos meios de agricultura (Brizzolla et al., 2020).

Os novos padrões sociais adotados pelas gerações mais recentes, tais quais a possibilidade de estudos e a valorização da urbanização, ocasionaram mudanças no meio rural (Kischener; Kiyota \& Perondi, 2015). Os mesmos autores ressaltam que a partir dos anos 70 intensificou-se o conflito entre as integrações rurais-urbanas e industriais-agrícolas, culminando numa barreira contra a sucessão parental.

Para transpor os ideais propostos pela empresa ou fazenda, faz-se necessário o emprego de questões cruciais que possibilitem o planejamento dessa sucessão de maneira gradativa e constante, pois os herdeiros deverão estar aptos assim que ocorrer a transferência da posse, seja em morte ou até mesmo em vida (Lobley, Baker \& Whitehead, 2012). O reconhecimento que o esquema de sucessão requer planejamento, constitui o primeiro passo para a validação e o sucesso a longo prazo (Sharma, 2006).

A sucessão familiar ultrapassou os limites da realidade e figurou-se na ficção em "Os Buddebrooks - Decadência de Uma Família", escrito em 1901 pelo ganhador do Nobel Thomas Mann, nele estão descritas quatro gerações de uma família e sua relação com uma firma de cereais, mostrando todos os empreendimentos investidos para manter as relações e detenção dos negócios frente os interesses dos indivíduos que compõe os laços familiares, geração pós geração (Araújo \& Oliveira, 2017).

No romance são evidenciados todos os acontecimentos que levam ao fracasso na transferência da posse, exemplificando que as relações com a empresa não dependem unicamente do sobrenome, mas também de fatores como afinidades pessoais, mudanças no comportamento da sociedade, transformações nos laços familiares e a falta de interesse por questões empresariais e de gestão (Boura, 2008). 
Os entraves enfrentados para que a sucessão familiar no meio rural seja desenvolvida de forma satisfatória, dependem de fatores pessoais e interpessoais dos membros que a compõe, sendo necessários estudos para poder elucida-los e exemplificalos conforme a realidade imposta pela sociedade moderna. O enfoque no romance "Os Buddenbrooks - Decadência de Uma Família”, correlaciona as características da atualidade com as descritas na ficção e determina os possíveis processos que podem levam ao sucesso ou ao fracasso.

\section{Sucessão Familiar Rural}

No Brasil a produção agrícola cujo prática é realizada pelos integrantes da família foi introduzida pelos imigrantes alemães em 1824, este modelo sofreu ajustes ao passar dos anos e apesar das mudanças impostas pela sociedade, sua importância continua sendo relevante para o crescimento econômico e social no meio rural (Santiago et al., 2019). Tal modelo de agricultura, contribuiu para que houvessem os primeiros meios familiares de cultivo para fins comerciais e de subsistência (Chemin \& Ahlert, 2010).

A sucessão familiar consiste na transposição dos meios sociais, do trabalho e da produção para os próximos sucessores, cuja a atividade juntamente com a interação dinâmica e profissional implica diretamente nos empreendimentos (Schineider, 2016). Portanto, a sucessão familiar rural determina a sobrevivência das empresas, fazendas ou pequenos sítios de produção.

As propriedades rurais familiares deverão ter como base as características elucidadas por Leal e Botinha (2012): a família é proprietária da empresa; a gestão pertence a um ou mais membros da família e os cargos de diretoria pertencem a seus componentes. O Estatuto da Terra, Lei nº 4.504 de 1964, determina as propriedades rurais como:

O imóvel que, direta e pessoalmente, é explorado pelo agricultor e sua família, lhes absorva toda a força de trabalho, garantindo-lhes a subsistência e o progresso social e econômico, com área máxima fixada para cada região e tipo de exploração, e eventualmente trabalhado com a ajuda de terceiros (Brasil, 1964).

O processo de sucessão familiar abrange desde empresas familiares com grandes extensões de terra até os pequenos produtores, onde constitui uma prática cultural comum em que os membros familiares contribuam com desenvolvimento das atividades rurais visando o sustento da família (Hunger et al., 2016). A caracterização família-produção-trabalho determina a sucessão de maneira abrangente (Matte \& Machado, 2016).

As empresas familiares representam 65\% do PIB brasileiro, empregam cerca de 75\% de trabalhadores e correspondem a $90 \%$ dos empreendimentos nacionais (Petroni, 2018). O IBGE (2006) ressalta que $84,4 \%$ dos estabelecimentos rurais tem base familiar e 74,4\% dos trabalhadores rurais pertencem a esses estabelecimentos.

Para validar os dados econômicos do Brasil com relação a sucessão parental Cobián (2017) salienta que para alcançar a perpetuação dos negócios necessita-se da cooperação e confiança dos membros envolvidos, garantindo estabilidade financeira, cultural e familiar. O modelo de sucessão sugere:

[...] a substituição do criador, fundador do empreendimento, para dar prosseguimento à obra criada e gerida pelo mesmo, porém com enfoque alterado, de estilos de liderança diferenciados e formação teórica e prática renovada em virtude do momento sócio econômico. (Nishitsuji, 2009).

Grandes empresas multinacionais tiveram seu início como empresas familiares e representam uma posição de destaque no setor econômico brasileiro, porém seus números não correspondem ao valor inicial de investimentos nesse setor, pois a grande maioria das empresas familiares sucumbem ao passar das gerações. A maioria das empresas familiares não ultrapassam a segunda geração, correspondendo a um percentual de $30 \%$ e somente $5 \%$ conseguem ultrapassar a terceira geração (Ward, 2004; Tolotti, Kruger \& Petri et al. 2018). 
A diminuição do quantitativo do trabalho rural por meio de familiares foi abordado por Karl Marx, onde previu que o modo capitalista com trabalhos assalariados e a produção em larga escala, determinariam a exclusão das fazendas ao longo dos séculos (Oliveira \& Filho, 2018). Porém dados recolhidos por MacDonald (2014) contrariando as previsões, quantificou os empreendimentos agrícolas e constatou-os como a estrutura dominante de agricultura no mundo.

\section{Os Buddenbrook e a Sucessão Familiar}

Em 1901 era lançado o primeiro livro do escritor alemão Thomas Mann, intitulado "Os Buddenbrook - Decadência de Uma Família", que se tornou rapidamente impactante dentro da literatura mundial e em 1929 ganhou o Nobel de Literatura por esta obra (Araújo \& Oliveira, 2017). A história está fundamentada em quatro gerações de uma mesma família, correspondendo a um período de 42 anos e acompanhando o desenvolvimento, ascensão e queda de uma firma de cereais e a sucessão familiar que a governa.

O início do livro está centrado no primeiro patriarca da família, o sênior Johann, e a partir dele há uma expansão constante dos negócios familiares, onde estão envolvidas as relações de todos os membros e crescimento dos empreendimentos da firma. As responsabilidades com a empresa e com o sobrenome da família, o leva a adquirir uma postura rígida com seus filhos, objetivando o comprometimento dos seus descendentes.

A firma apresenta ligeiro decréscimo financeiro após a morte de Johann, onde seu filho mais velho, Jean Buddenbrook, recebe a liderança da empresa e assume uma postura que difere da anterior. Seus filhos são orientados desde pequenos a agir de acordo com a ética proposta pela família, determinando que o filho mais velho assuma a liderança, os filhos mais novos auxiliem nos empreendimentos familiares ou prestem serviços a outras firmas para aquisição de experiência e as filhas consigam matrimônio com outros governantes de empresas visando a expansão dos negócios.

A formação familiar centralizada na figura masculina e as constantes mudanças que a modernidade da época apresentava, foram os primeiros desafios para as próximas gerações, fatores apresentados por Oliveira e Filho (2017):

Em uma sociedade preparada para as mudanças da modernidade, os valores familiares parecem também condenados a se modificar. Aspirações pessoais, que outrora foram sacrificadas pelo bem maior da empresa, agora ameaçam decompor uma dinastia caracterizada pelo esforço, comprometimento e trabalho árduo.

A terceira geração corresponde aos netos Thomas, Tony, Christian e Clara, ao qual fica a cargo do primeiro assumir a liderança da firma, estando descrito por Thomas Mann (p. 66, 1901): "Thomas (Buddenbrook), desde o seu nascimento, estava destinado à profissão de comerciante". Ressaltando o compromisso em que negócios deveriam ser unicamente sucedidos pelo filho mais velho, caracterizando a hegemonia do masculino sobre a figura feminina (Boura, 2008).

Essa geração na família é descrita por Oliveira e Filho (2017):

O neto mais velho, Thomas, fora criado pelo pai conforme era a vida de um mercante, desde cedo aprendeu os ofícios do negócio, acompanhava o pai ao trabalho e lhe fora ensinado os valores morais para o sucesso no mercado: todas as atitudes deveriam se ater às influências que teriam nos negócios, as amizades e conversas deveriam ser de tal modo que não prejudicassem a imagem da empresa, relações exclusivamente com a elite mercantil.

Ainda na terceira geração, o chefe da família adentra no caminho político e social, se torna senador e passa a dividir seu tempo entre a administração da firma e os deveres com o senado. Esse novo passo acaba causando-lhe cansaço e frustação, e à medida que o tempo vai passando, assuntos referentes a família e culturais são esquecidos ou ignorados e os laços familiares começam a se desfazer. 
Outras figuras importantes são os irmãos do senador, Christian e Tony, no qual o primeiro acaba diminuindo o capital da empresa devido ao seu estilo de vida e a segunda se casa com um comerciante que lhe rouba e ocasiona um desfalque nos empreendimentos da família.

Por fim, a quarta geração é focada no bisneto e filho único, Hanno Buddenbrook, que desde da infância não tem aptidão e nem interesse pelos negócios da família, ocupando seu tempo e prazeres com a música e afins. Apesar dos esforços contínuos e gradativos do pai, a empresa não consegue sobreviver as adversidades e já não há mais sucessores "legais" para liderar a firma.

\section{Metodologia}

Para quantificação dos procedimentos metodológicos foram realizadas pesquisas com caráter qualitativo, visando o aprofundamento sobre a sucessão familiar e todas as bases e pilares que a compõe, esse método de pesquisa é citado por Gonçalves e Meirelles (2004) ao determinar que a investigação de valores, atitudes, motivações e percepções, acerca de qualquer assunto ou pesquisa seja compreendido por todos(as).

A pesquisa qualitativa aqui realizada é direcionada para a validação do objeto de estudo apresentado, fator citado por Denzin e Lincoln (2006):

A pesquisa qualitativa envolve uma abordagem interpretativa do mundo, o que significa que seus pesquisadores estudam as coisas em seus cenários naturais, tentando entender os fenômenos em termos dos significados que as pessoas a eles conferem.

A pesquisa bibliográfica e documental procura atender todas as necessidades do tema pesquisado, visto que o apoio sobre livros, artigos científicos, manuais e publicações em formato digital de quaisquer naturezas, possam auxiliar na procura e exposição de informações e dados (Chemim, 2015). A partir dessa perspectiva foram feitas buscas em bases de dados acadêmicos como Periódico Capes, Google Acadêmico e SciELO e uma leitura avaliativa referente ao livro "Os Buddenbrook - Decadência de uma Família".

Autores reconhecidos sobre o tema abordado nesse artigo como Santiago, Kischener, Kiyota e Perondi, tiveram seus escritos amplamente estudados e referenciados, e a partir deles foram obtidas as análises necessárias para contextualização sobre a sucessão familiar em conjunto com Os Buddenbrook, para assim poder determinar os aportes que são necessários para o entendimento dos fenômenos em estudo (Pereira et al., 2018).

Com base nos métodos qualitativos foram determinados os parâmetros que levam a sucessão familiar, bem como os empecilhos e entraves na perpetuação de empresas, avaliando os fatores que contribuem para ascensão ou queda de um empreendimento rural, tomando como referência o romance manniano e assim poder traçar um elo entre as situações vividas na ficção correlacionando com a atualidade.

\section{Resultados e Discussão}

Para compreender a sucessão familiar apresentada em "Os Buddenbrook" a Tabela 1. expõe as gerações, seus respectivos governantes e os principais eventos que ocorreram durante o processo sucessório, dessa forma é evidenciado os meios e trajetos que determinaram o fim da firma, e os fatores apresentados estão de acordo com estudos realizados por Santos et al. (2017) que apontou algumas características como o preparo do sucessor, do sucedido, da família e do empreendimento. 
Tabela 1. Relação entre as gerações de governantes da família Buddenbrook e as características que ocasionaram a sucessão familiar.

\begin{tabular}{|c|c|c|}
\hline Gerações & Líder/Governante & Principais Características \\
\hline $1^{\circ}$ geração & Johann Buddenbrook & $\begin{array}{r}\text { Expansão dos negócios; ensinamentos sobre os valores } \\
\text { culturais e familiares; preparo do sucessor. }\end{array}$ \\
\hline $2^{\circ}$ geração & Jean Buddenbrook & $\begin{array}{c}\text { Diminuição dos aspectos financeiros da firma; centralização } \\
\text { dos negócios na figura masculina e banalização da mulher; } \\
\text { mudanças sociais e empresariais; perpetuação da tradição } \\
\text { familiar. }\end{array}$ \\
\hline $3^{\circ}$ geração & Thomas Buddenbrook & $\begin{array}{c}\text { esquecimento dos valores familiares; despreparo com relação } \\
\text { ao sucessor. }\end{array}$ \\
\hline $4^{\circ}$ geração & Hanno Buddenbrook & $\begin{array}{c}\text { Falta de aptidão e desinteresse pelos negócios familiares; } \\
\text { gosto pessoal pela música e afins; fim da sucessão. }\end{array}$ \\
\hline
\end{tabular}

Fonte: Autores.

$\mathrm{Na} 1^{\circ}$ geração do romance é apresentado o patriarca Johann que ensina a importância dos valores familiares concomitantemente com os valores empresariais, e assim inicia a preparação do sucessor por meio da vivência na prática e da tomada de decisão, em estudos com produtores de feijão e de café, Silva et al. (2017) verificaram que há pouco interesse na sucessão familiar principalmente dos filhos mais novos, porém em alguns casos, os filhos mais velhos por já terem a experiência de campo, demonstraram interesse em suceder seus pais.

A valorização da cultura familiar constitui um meio para que ocorra a sucessão de um empreendimento através das gerações, pois cabe a cada gestor perpassar a seus filhos a importância dos negócios familiares, motivando-os a continuar o legado no qual lhes serão entregues. Atualmente esses valores estão sucumbindo, como foi demonstrado por Brizzola et al. (2020) em estudos com propriedades rurais, destacando que um percentual acima de $80 \%$ não recebe orientação sobre sucessão familiar e aproximadamente $65 \%$ não realizam nenhuma atividade voltada para sucessão.

O primeiro passo para a sucessão familiar é o planejamento, determinando os possíveis sucessores e a melhor forma de inseri-los no contexto empresarial, como aborda Santiago et al. (2019) em análises da sucessão com produtores de leite, exemplificando que as fazendas iniciam seu modelo de sucessão tardiamente (quando o fazem), dessa forma o empreendimento está fadado ao fracasso, pois no lugar dos sucessores haverá somente herdeiros.

Os mesmos autores listam aspectos que devem ser levados em consideração, sendo eles: preparação dos filhos para o empreendedorismo; mostrar os horizontes e possibilidades a cada filho em relação aos negócios das fazendas; conhecer os projetos pessoais de cada filho; preparo do sucessor; autopreparação como sucedido; compartilhar a gestão da propriedade com seus filhos; determinar a remuneração e participação nos investimentos; formalizar parcerias com o sucessor; idealizar e pôr em prática o plano sucessório e transferir a posse para o sucessor.

A banalização da mulher frente aos negócios se torna mais evidente na segunda geração, a qual fica explícito que somente um homem deve herdar a gestão da empresa familiar, esse preconceito com relação a questão de gênero tem sofrido mudanças ao longo dos anos, porém ainda é um traço marcante, como pontua os autores Teston e Filippim (2016) ao afirmarem o tabu existente na relação da figura feminina com a administração dos empreendimentos familiares, configurando um preconceito estrutural e patriarcal que sobrevive ao longos dos séculos. 
O êxodo rural foi marcado pela constante imigração das mulheres para a zona urbana durante as duas últimas décadas (Castro \& Aquino, 2008), constatando essa realidade Silva et al. (2017) em estudos com populações rurais, colheu relatos sobre questões de sucessão familiar com produtores rurais e verificou que a gestão dos empreendimentos agrícolas era incentivada somente aos homens, já as mulheres eram estimuladas a irem para a cidade e concluírem algum curso superior.

Outro aspecto bastante evidenciado durante a liderança do segundo patriarca foi a mudança social e econômica que a modernidade impôs e, a partir dela, houve uma queda nos empreendimentos da firma devido a não adaptação do gestor a essa nova condição. Estudos realizados por Kischener, Kiyota e Perondi (2016) com sucessão geracional na agricultura, elucidaram que a modernização determinou a elevação da produção agrícola por meio da tecnificação, insumos, créditos governamentais, dentre outros, porém ocasionou uma nova padronização social, como a melhoria em acesso aos estudos presentes nas regiões metropolitanas.

A perpetuação da tradição familiar aos filhos e possíveis sucessores, cria um ambiente de afeto sobre todo o trajeto realizados pelos pais, desta forma, os descendentes ficam sensibilizados e encorajados a dar continuidade aos empreendimentos familiares. Os pais objetivam se aposentar e desejam que seus filhos permaneçam no campo dando continuidade a seus anos de trabalho, assim fazendo com que a história da família seja perpetuada para as próximas gerações (Lobley, 2010).

Durante a $3^{\circ}$ geração da família Buddenbrook, o líder da firma consegue se eleger para o senado e, então, passa a dividir o seu tempo com a empresa e os trabalhos políticos, causando-lhe cansaço e frustação. Essa divisão do tempo com relações totalmente distintas ocasiona o rompimento de uma das atividades ou de ambas, pois os trabalhos não são otimizados e a sucessão requer atenção, tempo e preparação a longo prazo, situação evidenciada por Stuani et al. (2016) ao analisar a sucessão em pequenas propriedades rurais e constatar que as relações do sucessor com o sucedido devem ser priorizadas.

$\mathrm{O}$ esquecimento dos valores familiares constitui uma problemática constante durante o processo sucessório, pois as características ligadas ao histórico social-cultural familiar devem ser dimensionadas a todas as fases da vida do futuro sucessor, pretendendo com isso que o mesmo adquira gosto pela atividade na qual irá desempenhar. Em pesquisas sobre gestão de fazendas brasileiras, Vieira (2013) destaca que há valorização das questões operacionais e administrativa, bem como o abandono de um plano estratégico que vise englobar as relações familiares com os empreendimentos.

O despreparo com relação aos sucessores é uma das principais causas do declínio das empresas e populações rurais, corroborando com os dados obtidos pelo IBGE (2010) indicando uma diminuição de 2 milhões de pessoas no meio rural e totalizando um percentual de 15,6\% da população brasileira. De acordo com Silva et al. (2017) a população urbana teve aumento percentual significativo no período de 2001 a 2012, partindo de $83,77 \%$ para $84,83 \%$, respectivamente.

O processo de preparação do sucessor deve ser iniciado na infância e finalizado quando a sucessão estiver formalizada, as etapas são descritas por Burton e Walford (2005) determinando que o tempo seja dividido entre as atividades agrícolas da fazenda e os estudos, pois assim, funções administrativas e de responsabilidades são vivenciadas e poderão ser postas em prática quando a liderança estiver na mão do filho.

O fim do processo de sucessão e a decadência da firma é relatado durante a $4^{\circ}$ geração, visto que o sucessor não tinha aptidão pelos negócios empresariais e mantinha uma relação de gosto pessoal com a música e afins, estas condições foram expostas por alguns autores em estudos com áreas de agrárias, como: a falta de interesse do filho (Zanin et al., 2014); falha na preparação do sucessor (Stuani et al., 2016) e o não incentivo governamental por meio de políticas públicas voltadas para a zona rural (Wink, 2017).

Kischener, Kiyota e Perondi (2015) listam os fatores que podem levar ao fracasso na sucessão familiar rural: a não valorização da questão histórica; a exclusão do gênero feminino; a renda do sucessor; a expansão da escolarização e a procura por estudos em zonas urbanas; os projetos pessoais dos filhos; o modo de vida urbano; a influência da própria comunidade rural e o trabalho que pode não ser compensatório pela falta de estruturação tecnológica e rentabilidade. 


\section{Conclusão}

O processo sucessório presente em "Os Buddenbrook - Decadência de Uma Família” serve como parâmetro para a sucessão familiar no meio rural, visto que os problemas e entraves apresentados no romance podem ser facilmente encontrados em propriedades rurais. Com base na obra de Thomas Mann, os temas abordados puderam ser discutidos e, então, conclui-se que as relações familiares formam os pilares na construção do sucessor.

Diante das situações encontradas fica evidente que existe fatores que devem ser levados em consideração na escolha do futuro sucessor, cabendo ao patriarca determinar a melhor forma de planejamento em relação aos filhos, respeitando todas as relações e pretensões individuais de cada indivíduo.

A sucessão familiar deve ser vista como um processo e não como um evento, pois partindo dessa premissa, haverá a formação de sucessores e não somente de herdeiros. Portando, a análise dos acontecimentos contidos na ficção auxilia na formação dos filhos e filhas, objetivando que estes possam obter a liderança das propriedades rurais e, assim, poder conceber a perpetuação dos negócios familiares.

Com base no que foi analisado e apresentado neste trabalho e considerando uma continuidade de pesquisa, são necessárias abordagens futuras sobre a sucessão familiar no meio rural, visto que a sociedade não é estática e ocorrem transformações e mudanças ao passar do tempo, desta forma, os modelos sucessórios podem requerer formas e modelos inovadores.

\section{Referências}

Araújo, L. F. \& Oliveira, P. C. (2017). Reflexões éticas sobre a família e a empresa: leituras a partir de Buddenbrooks de Thomas Mann. Revista de Estudos Jurídicos UNA, 3 (1), 148-164.

Boura, A. I. (2008). Hegemonia do masculino e triunfo do feminino no romance Buddenbrooks de Thomas Mann. Revista Filosófica de Coimbra, vol. 17 (34), $535-550$.

Brasil (1964). Casa Civil. Estatuto da Terra. Obtido em: planalto.gov.br/ccivil_03/leis/14504.htm

Brizzolla, M. M. B. et al. (2020). Sucessão familiar em propriedades rurais. Research, Society and Development, 9 (10), 1-26.

Brizzolla, M.M.B. et al. (2020). A percepção dos gestores de propriedades rurais e o processo da sucessão familiar. Research, Society and Development, 9 (11), $1-25$.

Burton, R. \& Walford, N. S. (2005). Multiple sucession and land division on family in the South East of England: A counterbalance to agricultural concentration? Journal of Rural Studies, 21 (3), 335-347.

Castro, J. A. \& Aquino, L. (2008). Juventude e políticas sociais no Brasil. (Texto para discussão, 1335). Brasília: IPEA.

Cobián, M. V. R. (2017). Cultura y organización en la empresa familiar. Iztapalapa, [S.l.], (55) 119-141.

Chemin, B. F. \& Ahlert, L. (2010). A sucessão patrimonial na agricultura familiar. Estudo \& Debate, 17 (1), 49-74.

Chemin, B. F. (2015). Manual da Univates para trabalhos acadêmicos: planejamento, elaboração e apresentação. (3.ed.). Ed. Da Univates.

Denzin, N. K. \& Lincoln, Y. S. (2006). Introdução: a disciplina e a prática da pesquisa qualitativa. In: Denzin, N. K. \& Lincoln, Y. S. (Orgs.). O planejamento da pesquisa qualitativa: teorias e abordagens. 2. ed. Porto Alegre: Artmed, p. 15-41.

Gonçalves, C. A. \& Meirelles, A. M. (2004). Projetos e Relatórios de Pesquisa em Administração. São Paulo: Atlas.

Hunger, V. B. et al. (2016). Os desafios na sucessão familiar: a transcrição do conhecimento empresarial às novas gerações. IX EGEPE, Encontro de Estudos sobre Empreendedorismo e Gestão de Pequenas Empresas, Passo Fundo/RS.

IBGE (2006) - Instituto Brasileiro de Geografia e Estatística. Obtido em:https://agenciade notícias.ibge.gov.br/ agencia-sala- de-imprensa/ 2013-agenciadenoticias /releases/13721-asi-agricultura-familiar-ocupava-844-dos-estabelecimentos-agropecuarios.

IBGE (2010) - Instituto Brasileiro de Geografia e Estatística. Obtido em: http://censo2010.ibge.gov.br/sinopse/webservice/frm_urb_rur. php?codigo=311160.

Kischener, M. A., Kiyota, N., \& Perondi, M. A. (2015). Sucessão geracional na agricultura familiar: lições apreendidas em duas comunidades rurais. Mundo Agrario, 16 (33), 1-28.

Leal, E. A. \& Botinha, C. T. N. (2013). Análise das atribuições e da participação do controller no processo sucessório em uma empresa familiar. Contextus Revista Contemporânea de Economia e Gestão, 11 (2), 135-158. 
Lobley, M., Baker, J. R., \& Whitehead, I. (2012). Keeping it in the family: international perspectives on succession and retirement of family farms. London: Ahsgate.

Lobley, M. (2010). Sucession in the family farm business. Journal of Farm Management, 13 (12) 839-851.

Macdonald, J. M. (2014). Family farming in the United States. Usda. Obtido em: https://www.ers.usda.gov/authors/ers-staff-directory/james-m-macdonald/

Matte, A. \& Machado, J. A. D. (2016). Tomada de decisão e a sucessão na agricultura familiar no sul do Brasil. Revista Estudos Sociais, 18 (37), $130-151$.

Mann, T. (2016). Buddenbrooks: Os Decadência De Uma Família. Trad. Hebert Caro. Companhias das Letras.

Nishitsuji, D. A. (2009). O processo da sucessão em organizações familiares na microrregião de Cornélio Procópio. [recurso eletrônico]. Curitiba: Universidade Federal do Paraná.

Oliveira, W. M. \& Filho, J. E. R. V. (2018). Sucessão nas fazendas familiares: problemas e desafios. [recurso eletrônico]. Brasília: Ipea. ISSN: 1415-4765.

Pereira et al. (2018). Metodologia da pesquisa científica. UAB/NTE/UFSM.

Petroni, M. (2018). Empresas familiares representam 90\% dos empreendimentos do país. Jornal da USP. Obtido em: https://jornal.usp.br/atualidades/atualidadesem-dia-com-o-direito-boletim-18-10-empresas-familiares-representam-90-dos-empreendimentos-no-brasil/

Santiago, A. M. F. et al. (2019). Desafios e Perspectivas de Jovens Latino-americanos na Sucessão Familiar da Atividade Leiteira. Brasília:EMPRABA-DF.

Santos, A. P. et al. (2017). Processo Sucessório: Estudo de Caso em uma Organização Familiar de Pequeno Porte do Ramo Imobiliário Conduzida por Mulheres. Revista de Gestão e Secretariado, 8 (3), 157-183.

Schineider, S. (2016). Mercados e agricultura familiar. In: Marques, FC, Conterato, MA., Schneider, S. Construção de mercados e agricultura familiar: desafios para o desenvolvimento rural. Porto Alegre: Ed. da UFRGS.

Sharma, P. (2006). An overview of the field of family business studies: current status and directions for the future. In: Poutziouris, PZ, Smyrnious, KX, Klein, SB (Orgs.). Handbook of research on family business. Cheltenham: Edward Elgar, 25-55.

Silva, D. F. et al. (2017). As dificuldades de "passar o bastão": perspectivas da sucessão da propriedade entre produtores de comunidades rurais do município de campos gerais/mg. Retratos de Assentamentos, 20 (2), 240-261.

Stuani, C. et al. (2016). Jovens herdeiros: uma análise da sucessão familiar em pequenas propriedades rurais de Nova Araçá. [recurso eletrônico]. Passo Fundo: IX EGEPE.

Teston, S. F. \& Filippim, E. S. (2016). Perspectivas e Desafios da Preparação de Sucessores para Empresas Familiares. Rev. adm. contemp. 20 (5), $524-545$.

Tolotti, C. M. F., Kruger, S. D., \& Petri, S. M. (2018) Características do processo de sucessão familiar: uma abordagem em entidades rurais de Santa Catarina, Vivências: Revista Eletrônica de Extensão da URI, 14 (26), 97-109.

Vieira Filho, J. E. R. (2013). Heterogeneidad estructural de la agricultura familiar en el Brasil. Revista Cepal, (111) 103-121.

Ward, J. L. (2004). Perpetuating the family business. Palgrave Macmillan.

Wink, L. L. (2017). Perspectiva do processo de sucessão familiar em propriedades familiares produtoras de leite. [recurso eletrônico]. Lajeado: Universidade do Vale do Taquari - UNIVATES.

Zanin, A. et al. (2014). Gestão das propriedades rurais do Oeste de Santa Catarina: as fragilidades da estrutura organizacional e a necessidade do uso de controles contábeis. Revista Catarinense da Ciência Contábil, 13 (40), 09-19. 